This is an electronic reprint of the original article. This reprint may differ from the original in pagination and typographic detail.

Author(s): Silvennoinen, Johanna; Rousi, Rebekah; Jokinen, Jussi; Perälä, Piia

Title: $\quad$ Apperception as a Multisensory Process in Material Experience

Year: $\quad 2015$

Version:

Please cite the original version:

Silvennoinen, J., Rousi, R., Jokinen, J., \& Perälä, P. (2015). Apperception as a

Multisensory Process in Material Experience. In Academic MindTrek'15 :

Proceedings of the 19th International Academic MindTrek Conference (pp. 144-151).

Association for Computing Machinery (ACM).

https://doi.org/10.1145/2818187.2818285

All material supplied via JYX is protected by copyright and other intellectual property rights, and duplication or sale of all or part of any of the repository collections is not permitted, except that material may be duplicated by you for your research use or educational purposes in electronic or print form. You must obtain permission for any other use. Electronic or print copies may not be offered, whether for sale or otherwise to anyone who is not an authorised user. 


\section{Apperception as a Multisensory Process in Material Experience}

\author{
Johanna M. Silvennoinen \\ University of Jyvaskyla, \\ Department of Computer Science \\ and Information Systems, \\ P.O. Box 35, Fl-40014 \\ University of Jyvaskyla \\ $+358407494467$ \\ johanna.silvennoinen@jyu.fi
}

\author{
Rebekah Rousi \\ University of Jyvaskyla, \\ Department of Computer Science \\ and Information Systems, \\ P.O. Box 35, Fl-40014 \\ University of Jyvaskyla \\ $+358408053100$ \\ rebekah.rousi@jyu.fi
}

\author{
Jussi P. P. Jokinen \\ University of Jyvaskyla, \\ Department of Computer Science \\ and Information Systems, \\ P.O. Box 35, FI-40014 \\ University of Jyvaskyla \\ $+358408053670$ \\ jussi.p.p.jokinen@jyu.fi
}

\author{
Piia M. H. Perälä \\ University of Jyvaskyla, \\ Department of Computer Science \\ and Information Systems, \\ P.O. Box 35, Fl-40014 \\ University of Jyvaskyla \\ +358408054541 \\ piia.m.h.perala@student.jyu.fi
}

\begin{abstract}
Visual perspective has dominated experience research in humantechnology interaction for decades now. The neglect of other sensory modalities is gradually being addressed by scholars and designers, who investigate user experience based on touch, smell, taste, sound and even expressive bodily interactions. In cognitive and affective processes, user experience is always multi-modal, not just regarding perceived multi-sensory information, but also while perceiving through one modality we mentally construct information relevant to the other senses. This article reports the results of an experiment, where participants $(N=52)$ appraised materials either only by touching them or only by seeing. The results indicate that with certain affects, the logic of the appraisal depends on the modality. These results are discussed within the theoretical framework of mental content, apperception, and appraisal. Further, we discuss the relevance of the findings for material design, especially in the context of multimodal interaction.
\end{abstract}

\section{Categories and Subject Descriptors}

H.5 Information Interfaces and Presentation (e.g., HCI).

\section{General Terms}

Design, Human Factors.

Permission to make digital or hard copies of all or part of this work for personal or classroom use is granted without fee provided that copies are not made or distributed for profit or commercial advantage and that copies bear this notice and the full citation on the first page. Copyrights for components of this work owned by others than ACM must be honored. Abstracting with credit is permitted. To copy otherwise, or republish, to post on servers or to redistribute to lists, requires prior specific permission and/or a fee. Request permissions from Permissions@acm.org. AcademicMindTrek'15, September 22-24, 2015, Tampere, Finland

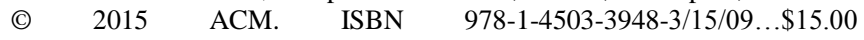
DOI: http://dx.doi.org/10.1145/2818187.2818285

\section{Keywords}

Apperception; multi-sensory experience; product design; design materials; context.

\section{INTRODUCTION}

The centrality of experience in human-technology interaction research has led to numerous studies focusing on different factors of technology-interaction. Much emphasis has been placed on the so-called hedonic aspects of interaction, such as aesthetics and emotion $[1,3,5,20,32,33]$. The current focus on hedonic aspects of technology-interaction has emerged, because the classic usability research paradigms have not been able to capture the richness of multidimensional holistic technology experience [30]. Human experience of technological artifacts is based on multidimensional encoding, and is constructed via multiple sensory modes. Thus, for instance, even if we perceive something just visually, the mental process that creates a representation of it integrates both visual and tactual contents.

Regardless, much focus has been placed on the visual modality in technology-interaction [e.g. 2, 15]. Thus, interest has been largely directed towards designing for vision, while designing for other modalities has not been investigated as extensively [15]. This emphasis is a result of the visual modality's primary role in biasing information for other senses [22, 27]. The centrality of vision in encountering artifacts has led to product design studies, in which products have been designed contrary to users' expectations [e.g. 4]. For instance, designing products with visualtactual incongruities have been found to often result in surprise, which positively affects the product-interaction $[6,15,16,17]$.

Additionally, as technology becomes more ubiquitous, information on multimodal experiences becomes increasingly important for design. The significance of material design also 
accumulates in technology-design, because the focus is not merely on hardware design, but on designs that encourage rich user experiences, such as the current designs of soft interactive technology [28]. In addition, designing artifacts for multisensorial technology-interaction contributes to the growing demand of coping with multimodal information flow [18]. However, the design of technological artifacts often focuses on different sensorial product properties separately, such as visual, tactual, auditory and olfactory product properties [13]. For instance, weight is considered primarily as a haptic property of an artifact. Evaluations of weight have been studied in terms of their effect on quality perceptions. In many product categories heavier artifacts are considered more valuable [14], important and serious [10]. Hard shiny materials have been found to elicit impressions of professionalism [12].

In order to understand the role of different modalities when people appraise technological products, modal-specific affective qualities need to be isolated within the total appraisal process. This requires detailed investigation of how people experience products, how material design properties are appraised, and the theorization of how people mentally represent information obtained through different modalities.

Mental representations have content, which is the subjective and meaningful part of the mental representation, and can therefore be understood as the experiential aspect of human-technology interaction $[9,24,25]$. The affective content of a representation may vary based on modal-specific information source. In addition, modality-related contents of mental representations can vary in relation to the other modalities. For example, a representation of a product with primarily tactual properties can have visual contents, although the interaction occurs only through touch. Specific textures and temperatures of materials, experienced via touch, can still be associated with colors, which is visual information [23]. Thus, mental representations cannot be reduced to pure perception, but rather involve other more complex mental processes such as apperception.

In apperception process, information from different sensory modalities as well as already existing mental information contents are integrated into a meaningful mental representation. Apperception can be described as 'seeing something as something' [7, 11, 24]. In the domain of tactual experience, apperception is 'tactually perceiving something as something'. Further, different contents have different sources in the human emotional process [26, 29]. For example, appraising something as warm is mostly based on a perceptual stimulus, whereas appraising something as useful requires associative information and reasoning. When people interact with artifacts, they combine information from different appraisal sources into a coherent mental representation. In this paper, we propose that the same affect may have different information sources depending on modality.

How information obtained via different sensory modalities is mentally represented contributes to the understanding of how to effectively design material experiences within technological artifacts. Thus, the purpose of the experiment was to investigate how people apperceive material information through different sensory modalities and what materials are considered suitable for different technological products.
The experimental design of the study was conducted accordingly in order to explicate the material information people encode when interacting with different materials. Following hypotheses were investigated:

H1: The interaction modality influences how materials are appraised with different affects.

$\mathrm{H} 2$ : The interaction modality influences the consistency of the appraisal of a material.

H3. The associations of individual affects differ between sensory modalities.

\section{METHOD}

\subsection{Participants, stimuli, procedure}

$N=52$ participants (age range 19-43, mean age 25.5 years, $S D=$ 5.8) were recruited for the experiment. The experimental design was a between-subjects design: the participants were divided into two independent groups called visual group and tactual group. The groups differed in sensory modalities used for perceiving the stimuli. In the visual group (VIS, $n=26,12$ male and 14 female), the participants were only able to perceive the stimuli through vision. In the tactual group, the participants perceived the stimuli only by sense of touch (TAC, $n=26,12$ male and 14 female).

Ten materials were used as stimuli. Materials were (a) stone, (b) linoleum, (c) wood, (d) cardboard, (e) hard shiny plastic, (f) fluffy fabric, (g) metal plate, (h) felt, (i) soft matt plastic, and (j) sateen (Figure 1). Materials were selected so that there was variance in how they looked and felt. The materials were cut as rectangles $(35.5 \mathrm{~cm} \mathrm{x} 35.5 \mathrm{~cm})$.

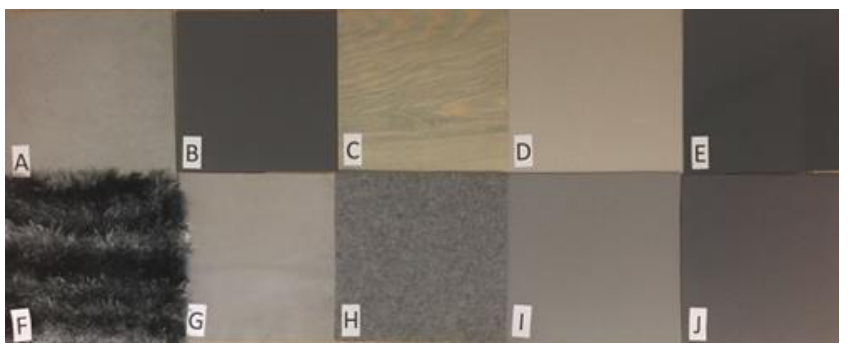

Figure 1. The materials of the experiment.

In the experiment, interaction with the materials was constrained for both groups. The visual group was only permitted to visually perceive the materials without touching them (figure 2). The tactual group was only allowed to touch the materials without visual inspection. In the tactual group, a 'touch box' (a cardboard covered with fabric, box with one of the materials inside) was presented to the participants (figure 2). The participants were allowed to use one hand inside the box to investigate the material.

The experiment was conducted in a laboratory environment to control sensorial stimuli of sounds and scents. The research procedure of the experiment was similar for both groups. The participants evaluated each material in a counterbalanced order (Latin square) by responding to a semantic differential questionnaire, described below. Each material was evaluated separately, and thus each participant filled the questionnaire ten times. 
After the participants had filled the semantic differential questionnaires, they answered a context questionnaire concerning the suitability of the materials for five different design contexts. When the participants answered the context questionnaire they were able to investigate and compare the materials. For the visual group, all materials were exhibited, and for the tactile group all the boxes with materials inside were available for touch based investigation.

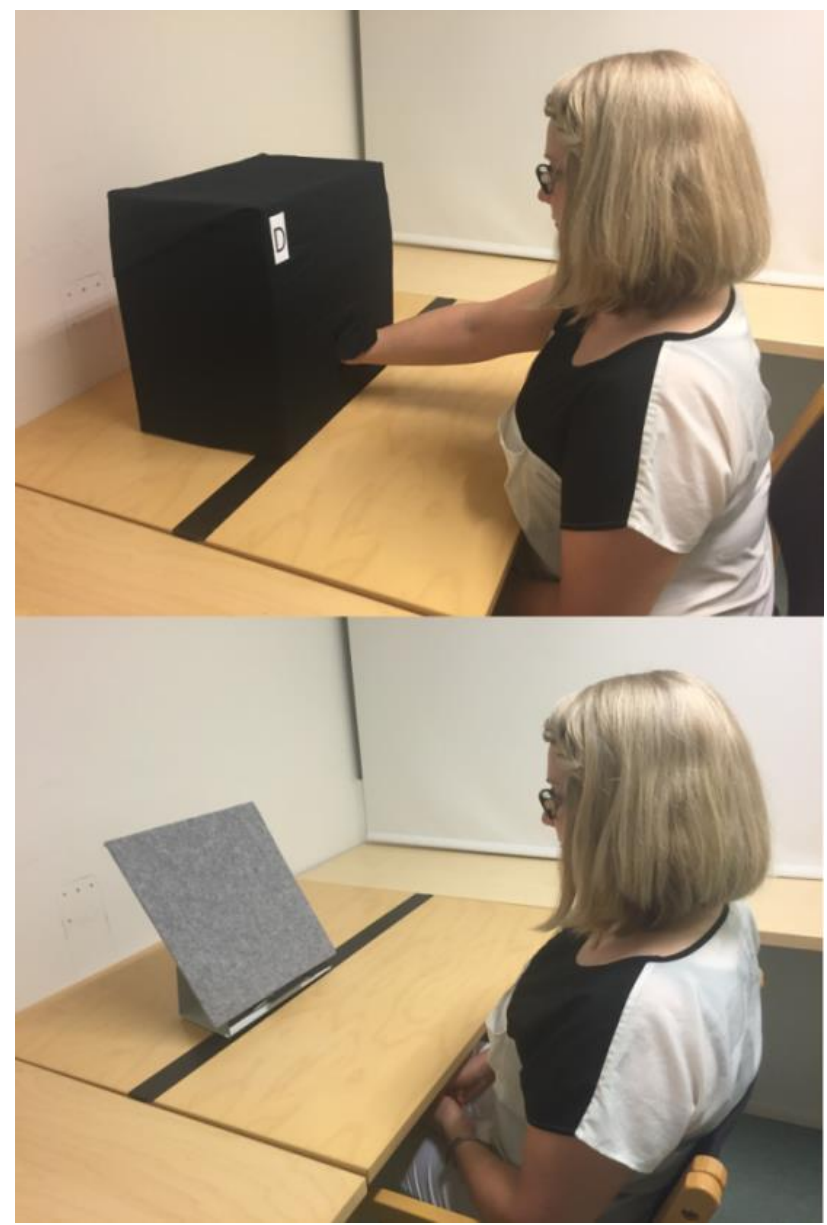

Figure 2. The experimental setup for tactile group (above), and for visual group (below)

\subsection{Questionnaires}

Two questionnaires were completed in the experiment: 1) a 9 point semantic differential questionnaire for the material evaluation; and 2) a questionnaire about the most optimal material for specific design contexts. The semantic differential questionnaire, filled separately for each material, included following adjective pairs: light-heavy, cold-warm, smooth-rough, thin-thick, murky-bright, hard-soft, and rising-flat. The adjectives were chosen from Osgood's list of affective pairs [21] to represent the perceptual information source of appraisal [29].

The context questionnaire concerned the suitability of the materials for five different design contexts: elevator interior, an interactive toy (e.g., a robot dog), a computer tablet case, a remote control, and wearable technology. For each context, only one material was allowed to be selected as the most optimal material.

\subsection{Data Analysis}

The first hypothesis concerned the interaction effect between the grouping variable (VIS/TAC) and the material. To test it, repeated measures analyses of variance with a between-factor were conducted for each of the adjectives separately, with material as the within-factor, and group as the between-factor. If a statistically significant interaction effect $(\alpha=.05)$ was observed, further inspections were carried out by visually inspecting the bar graphs of the means of the adjective between stimuli and groups.

The second hypothesis was tested with Levene's test for equality of variances between the two groups. The test was conducted separately for each adjective, and further for each material. This resulted in a large number of consecutive tests, and thus the level of statistical significance for testing $\mathrm{H} 2$ was lowered to $\alpha=0.01$. A statistically significant test result meant that the variance of the variable differed between the two groups, which was taken to indicate consistency differences between the groups: smaller variances indicated that the participants rated the materials similarly, that is, agreed with each other.

The third hypothesis was tested by calculating the Pearson correlation coefficients for the affects separately between the groups. In these calculations, the data were pooled across all ten stimuli.

\section{RESULTS}

\subsection{Semantic Differential Questionnaire}

No statistically significant differences were detected between the groups in evaluating heaviness of materials, $F(9,500)=1.75$, $p=.076$. Stone and Linoleum were the only materials appraised as heavy. Evaluations of all the other materials did not differ from each other. The participants were not able to differentiate the stimuli from each other with this affect. Further, all Levene's tests were non-significant, indicating that there were no differences in agreement between the groups. Weight evaluations conducted by touch (without lifting the material) or by visual inspection did not differ. Weight evaluations cannot be conducted without knowledge of the product context. Therefore, when the product context is lacking, just the overall evaluations, such as stone being evaluated as heavier than all the other materials, are conducted. For heaviness, neither $\mathrm{H} 1$ nor $\mathrm{H} 2$ was supported.

The interaction effect for the affect warm was statistically significant, $F(9,500)=2.0, p=.035$. Post-hoc inspection revealed that the tactual group evaluated linoleum warmer and wood colder than the visual group, while other materials were evaluated similarly in both groups. The evaluations in the visual group might have been influenced by the associations of wood and warmth as wood can be associated with fire. It may also have been apperceived in light of experiences with wood as a building material, existing in opposite to colder materials such as cement and steel for example [31]. In the tactual group, associations relied purely on tactual information, and in this group, linoleum was considered warmer. Considering warmth ratings, visual and tactual evaluations and associations are not easily carried out if the material is not familiar. There were no statistically significantly different variances of warmness for the different materials in the two groups. For warmth, H1 was supported, while $\mathrm{H} 2$ not. 
The interaction effect of roughness was statistically significant, $F(9,500)=2.05, p=.032$, and the post hoc inspection revealed that this difference was due to linoleum evaluations. Roughness of linoleum was evaluated lower in the visual group than in the tactual group. Further, Levene's test revealed that the differences of linoleum evaluations varied more extensively in the visual group than in the tactual group $\left(S D_{t}=0.99, S D_{v}=2.35, F(1,50)=\right.$ $22.53, p<.001)$. In the tactual group, the participants had more consistent evaluations and were able to represent more consistent sensory information concerning the roughness of the material. Conversely, the participants of the visual group could only explicate their impressions based on how familiar the material was. For roughness, both $\mathrm{H} 1$ and $\mathrm{H} 2$ received support.

The interaction effect of evaluating thinness of the materials was statistically significant, $F(9,500)=3.252, p=.001$. Further inspection revealed that linoleum was evaluated thinner in the visual group than in the tactual group. Variance of the thinness evaluations of linoleum was statistically significant between the groups $\left(S D_{t}=1.27, S D_{v}=2.12, F(1,50)=11.04, p=.002\right)$. Participants of the visual group did not represent consistent agreement of how thin linoleum was evaluated. In the tactual group, linoleum was considered thicker, and the participants were consistent in the evaluations. In addition, hard shiny plastic was evaluated thinner in the visual group than in the tactile group, but in both groups the variance of evaluations differed, indicating that information gained by the sense of touch does not enable systematic information retrieval of thinness of hard plastic material, nor does not visual inspection. Both $\mathrm{H} 1$ and $\mathrm{H} 2$ were supported by evaluations of thinness.

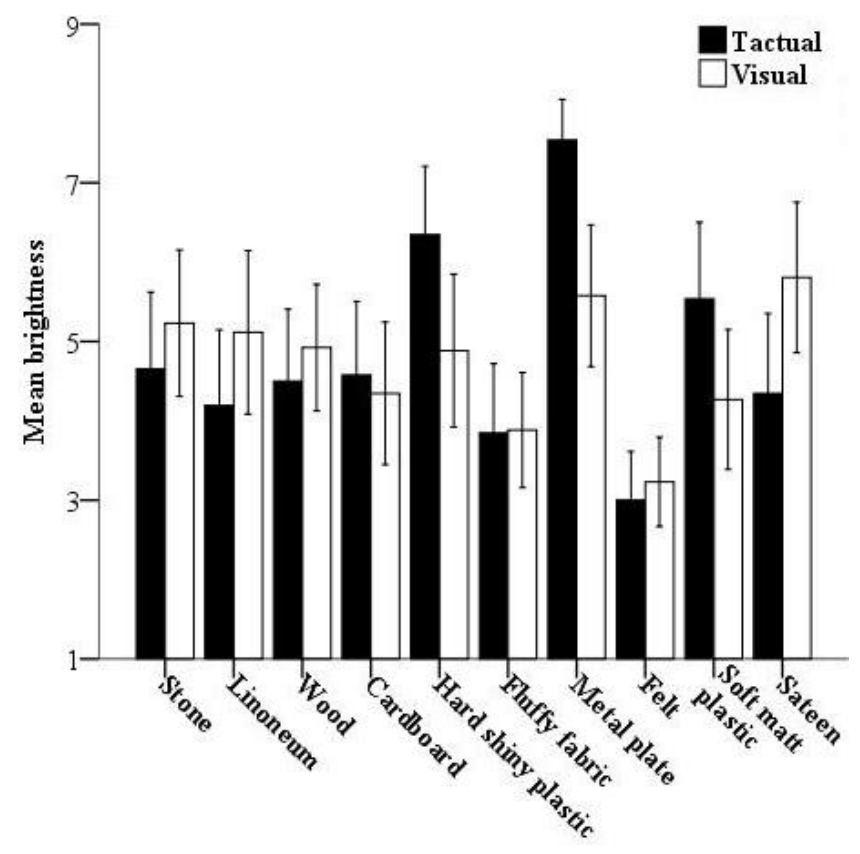

Figure 3. Mean brightness between the materials and the groups. Error bars indicate $95 \%$ CI.

The interaction effect was statistically significant concerning brightness, $F(9,500)=4.45, p<.001$. The observed differences are displayed in figure 3. Hard shiny plastic was evaluated brighter in the tactual group than in the visual group. Also, soft matt plastic was evaluated brighter in the tactile group than in the visual group. Overall, hard shiny plastic was evaluated to be brighter than soft matt plastic in the tactual group. Through tactile sensation, the participants were still able to differentiate evaluations of brightness between these two types of plastic, in which the information gained by the visual modality did not interfere in the appraisal process. Affects that are primarily visual can be evaluated with tactual information, if visual information is not available. This result implies that with tactual information, brightness evaluations can be conducted, but the information is obtained through appraisals of some different affects.

The metal plate was evaluated brighter in the tactile group than in the visual group. The tactile sensation of the metal plate was apperceived as bright. Variance difference in the evaluations between groups concerning metal plate was statistically significant $\left(S D_{t}=1.27, S D_{v}=2.12, F(1,50)=10.42, p=.002\right)$. The visual group varied in agreement concerning brightness, and conversely, the tactile group evaluated consistently the material as bright, even though shiny metal surfaces are sensitive to stains and murkiness. However, without visual information on the material, these kinds of appraisals do not occur. Fabric was evaluated as less bright in the tactile group than in the visual group. These findings on brightness support both $\mathrm{H} 1$ and $\mathrm{H} 2$.

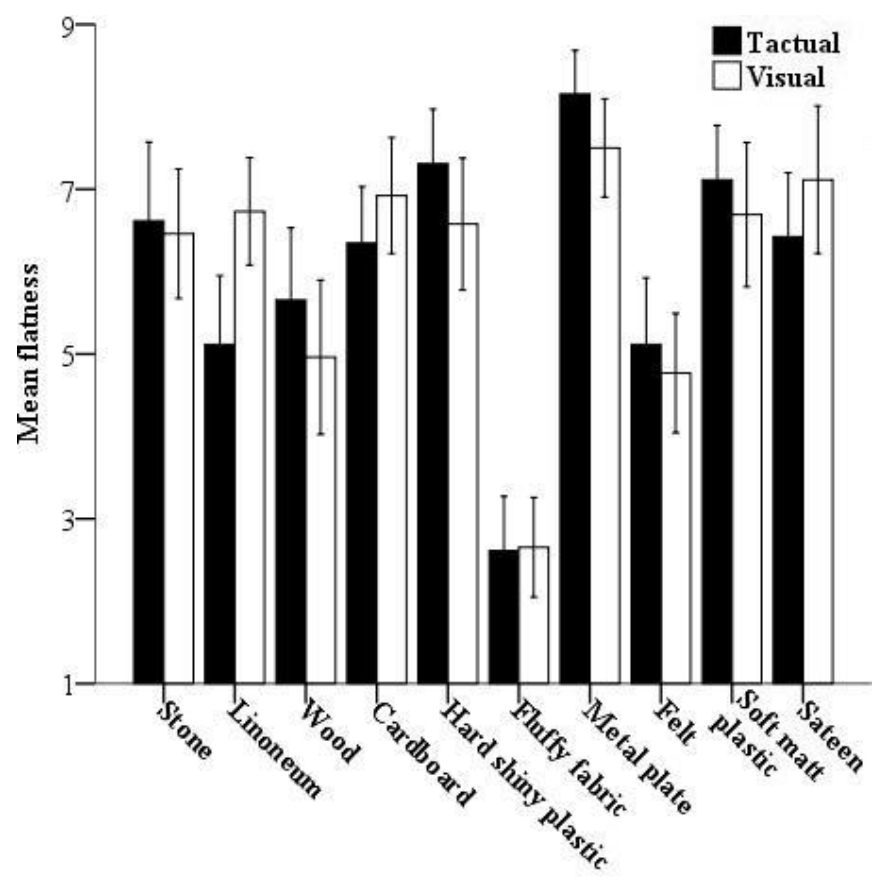

Figure 4. Mean flatness between the materials and the groups. Error bars indicate $95 \%$ CI.

The interaction effect, that the stimuli was evaluated differently between the groups concerning flatness was statistically significant $F(9,500)=2.97, p=.002$. Post-hoc inspection revealed that the tactual group evaluated linoleum as more rising than the visual group. Fluffy fabric was evaluated as the most rising material in the both groups, and offset as the flattest (figure 4). Linoleum was apperceived as more rising in the tactile group than in the visual group. Finger tips are more efficient in sensing subtle differences in the material surface than visual inspection. 
The variance of the evaluations between groups was not statistically significant. Thus, the findings on flatness support $\mathrm{H} 1$ but not $\mathrm{H} 2$.

The interaction effect between the modality groups and stimulus evaluations concerning hardness of the materials was statistically significant, $F(9,500)=2.1, p=.026$. Post-hoc inspection revealed that the tactual group evaluated linoleum, soft plastic, and fabric as harder than in the visual group. Variance of linoleum evaluations was different between the groups $\left(S D_{t}=1.41, S D_{v}=\right.$ $2.30, F(1,50)=41.5, p<.001)$. Again, the visual group varied in agreement, and the tactile group was more consistent. Evaluations concerning hardness of linoleum are more easily carried out through touch than vision. Overall, stone, hard plastic, and metal plate were evaluated as hard materials. Fluffy fabric and felt as soft materials, and the rest of the stimuli were rated between these ends. All the evaluations, besides of linoleum, did not differ according the groups. These findings support both $\mathrm{H} 1$ and $\mathrm{H} 2$.

Correlative inspection, testing $\mathrm{H} 3$, revealed that the association between bright and warm and bright and hard differed between the modality groups. Whereas, in the tactual group, brightness correlated positively with warmth $(r=.38)$ and softness $(r=.31)$ in the visual group the correlations were almost nonexistent $(r=$ .06 and .15 ; both correlation differences were statistically significant). Brightness is primarily a visual property of materials. Therefore, tactual experience of brightness is conducted through evaluations of hardness and warmness of the material. Hardness and warmness associate which each other in the mental representations of brightness in the visual group, which indicates that the coding of the affect is modality-dependent. In the associative framework, hardness and softness do not associate abstractly, but inside the modality. Tactually, brightness and warmness are associated which each other. Therefore, the logic of the affect is modality-dependent.

\subsection{Appropriate Material Context}

Identification of the most appropriate materials for five different design contexts was conducted by counting frequencies from the participants' selections. Frequencies were counted separately for both sensory modality groups in each design context. Material selections for these five different design contexts are presented in table 1 (from the ten materials stone, wood and cardboard are excluded from the table due to their low selection frequency). The results presented in the table are discussed according to which material was selected as the most appropriate option and the option differing most between the tactual and the visual group.

In both modality groups, 'metal plate' was selected as the most appropriate material for elevator interior design. 'Hard shiny plastic' was considered as the second best option for elevator interior design in the tactual group, but in the visual group none of the participants appraised the material to fit this design context. Visual inspection of hard shiny plastic can reveal more functionality attributes associated to this material than through tactual information, which might affected the difference between the groups. 'Fluffy fabric' was considered as the most appropriate material for an interactive toy (e.g., a robot dog toy) in both groups. However in the visual group the selection was not highly mutual since there was only one frequency difference between 'fluffy fabric 'and 'soft matt plastic'.

In the tactile group, the most appropriate material for a tablet computer case was 'hard shiny plastic'. On the contrary, in visual group none of the participant selected 'hard shiny plastic' as the most appropriate material for this context. In the visual group, the

Table 1. The most appropriate materials for five design contexts in the tactual and visual group.

\begin{tabular}{|c|c|c|c|c|c|c|c|c|c|c|}
\hline \multirow{2}{*}{ Material } & \multicolumn{2}{|c|}{ Elevator } & \multicolumn{2}{|c|}{ Interactive toy } & \multicolumn{2}{|c|}{$\begin{array}{l}\text { Case for tablet } \\
\text { computer }\end{array}$} & \multicolumn{2}{|c|}{ Remote control } & \multicolumn{2}{|c|}{$\begin{array}{l}\text { Wearable } \\
\text { technology }\end{array}$} \\
\hline & TAC & VIS & TAC & VIS & TAC & VIS & TAC & VIS & TAC & VIS \\
\hline Linoleum & 2 & 7 & 0 & 0 & 2 & 2 & 2 & 3 & 0 & 3 \\
\hline $\begin{array}{l}\text { Hard shiny } \\
\text { plastic }\end{array}$ & 6 & $\mathbf{0}$ & 6 & 1 & 8 & $\mathbf{0}$ & 10 & 6 & 1 & 0 \\
\hline $\begin{array}{l}\text { Fluffy } \\
\text { fabric }\end{array}$ & 0 & 0 & 8 & 8 & 0 & 2 & 0 & 1 & 3 & 3 \\
\hline Metal plate & 9 & 9 & 5 & 5 & 1 & 1 & 2 & 0 & 0 & 0 \\
\hline Felt & 2 & 0 & 3 & 4 & 5 & 9 & 0 & 1 & 9 & 2 \\
\hline $\begin{array}{l}\text { Soft matt } \\
\text { plastic }\end{array}$ & 3 & 1 & 3 & 7 & 3 & 1 & 9 & 10 & 2 & 4 \\
\hline Sateen & 2 & 1 & 1 & 1 & 4 & 8 & 2 & 2 & 10 & 14 \\
\hline
\end{tabular}


ratings of the most appropriate material for the tablet computer case were not unanimous. The difference between the first and the second option was only one frequency. The most appropriate material for this context in the visual group was 'felt', and the second best was 'sateen'.

In the tactual group, the most appropriate material for a remote control was 'hard shiny plastic'. However only one frequency separated the first and the second best material option ('soft matt plastic'). In the visual group, the most appropriate material for the remote control was 'soft matt plastic'. 'Sateen' was considered as the most appropriate material for wearable technology in both of the groups. In the visual group the selection was unanimous, but in the tactual group there was only one frequency difference between 'sateen' and 'felt'.

Frequencies of selected materials were compared between the tactual and the visual groups. Comparison showed that 'hard shiny plastic' and 'felt' were materials that differed most in frequencies in different contexts. 'Hard shiny plastic' differed most in the elevator interior design (difference 6 selections), interactive toy (difference 5 selections), tablet computer case (difference 8 selections), and remote control (difference 4 selections) design contexts and 'felt' in the wearable technology (difference 7 selections) context.

Comparing the selections of the most suitable materials between the groups 'hard shiny plastic' and 'felt' were the materials that differed the most in different design contexts. Evaluations of 'hard shiny plastic' differed most in the elevator, interactive toy, tablet computer case, and remote control design contexts and 'felt' in the wearable technology context.

\section{DISCUSSION}

In this study the focus was on investigating the differences of affective representations between groups, which appraised product materials through varying sensory modalities. All three hypotheses of the study received support, although not with all materials and affects. However, the results are clear enough to support the general proposition put forth in this paper, that the affective content of a mental representation is potentially dependent on the modality of the information, which is used to construct that representation. For example, the participants rated linoleum rougher, if they were only allowed to touch it, compared to if they were only allowed to look at it. Further, the tactual group was more consistent in their appraisals of the roughness of linoleum than the visual group.

The finding above can be explained by appraisal theory, which posits that emotional experience is the result of a cognitive process, in which different information sources are integrated in a central representation [8]. These information sources are sensory, associative, and reasoning, and the results of the study reported here suggest that different affective contents are based on information from different sources, depending on the modality of the information. Thus, for example, touching linoleum gives a different roughness appraisal than looking at it. While touch gives robust sensorial information on linoleum's roughness, vision does not, and thus the user is left with association and reasoning. Because people have different memories and ways of reasoning, there is more variance in vision-based appraisals of linoleum than in touch-based appraisals.
In addition, evaluations of tactile material experiences differ according to the familiarity of the material [e.g. 19]. Therefore, familiarity with the material affects consistency of evaluations and the information sources that are used in appraising the tactile sensation. If the material is unknown, the evaluations rely more on the information obtained via tactual sensation than on the associations brought forth with previous experiences with the material. Moreover, mental representations of different affects are modality-dependent. Tactual appraisals of primarily visual material properties are represented through a combination of different affects. For example, tactual evaluation of brightness is conducted through evaluations of hardness and warmth of a material.

The contextual material preferences are drawn from the information source of associations, which function through familiarity. The results of the most appropriate materials for different technological design contexts function as the basis for understanding the appraisals of conventional and appropriate material design. That is, even in experimental situations, people still resort to providing information obtained through prior experiences, giving details of what is apparently 'known' or remembered rather than actively imagining and taking risks with their connections between materials and application contexts. With this knowledge, product designers are able to design contrary to the users' expectations, which can result in a surprise during product-interaction. In addition, modality-dependent logic of affect implicates different material design solutions for technological products, for instance concerning tactual representations of brightness.

\section{CONCLUSION}

Human-technology interaction involves different modalities with altering appraisals, which lead to variance in the affective contents that users associate with products in their minds. The study reported here illustrates the concept of apperception, which means that product qualities are not perceived as objective, but instead are constructed in a mental process, which makes the products and their properties meaningful to the users. This knowledge can be used and manipulated when designing interactive products, particularly in increasingly embodied fields such as the internet of things (IoTs), soft technologies, and even when developing technological products for enabling multi-sensory experiences. We have found that touch plays a fundamental role in humantechnology interaction, whether that be via touch directly or via vision. Through vision, human beings mentally construct (imagine) tactile experience, by connecting what is seen, with what is remembered and 'known'. This was demonstrated by the way people attached the material qualities to specific and familiar design contexts.

Here, the philosophical concept of apperception was given a psychological formulation in terms of appraisal, which is defined as the cognitive evaluation leading to affective contents of mental representations $[8,9]$. The main conclusion of the study is that material properties which are primarily visual, such as brightness, are encoded tactually through associations with different affects than in visual material experience. Tactual brightness evaluation is apperceived and mentally constructed through experiencing hardness and warmth of materials. Therefore, the logic and the process of the affect are modality-dependent. This means that for example, desired impressions and affects can be tactually designed into products, such as the use of hard, shiny materials, 
which have been found to elicit impressions of professionalism [12]. Designers can benefit from this knowledge in their work, by focusing on the sensorial material properties and the ways in which these properties can be designed to elicit affective qualities.

Modality-related affective aspects in the experience of technological products are important in experience driven design processes. Our results show that contrary to what is believed with the more dominant sensory modality of vision and its ability to communicate, in many cases vision leads to disperse understandings of materials and their properties. That is, people imagine materials and their applications with more variation when perceiving via sight, than while perceiving through other sensory modalities such as touch. This means that not only can there be less predictability when designing products with visual emphasis, but this disparity may also provide more opportunities to design for affective experiences such as surprise in product-interaction.

\section{ACKNOWLEDGMENTS}

The research has been supported by the Finnish Funding Agency for Technology and Innovation (TEKES) and the Finnish Metals and Engineering Competence Cluster (FIMECC) programme UXUS (User experience and usability in complex systems), and Doctoral Program in Computing and Mathematical Sciences (COMAS).We thank the research assistants for conducting the experiments.

\section{REFERENCES}

[1] Bargas-Avila, J. and Hornbaek, K. 2011. Old wine in new bottles or novel challenges? A critical analysis of empirical studeis of user experience. In Proceedings of the SIGCHI Conference on Human Factors in Computing Systems, CHI'11, ACM Press, New York, NY, 2689-2698.

[2] Crilly, N., Moultrie, J., and Clarkson, J. P. 2004. Seeing things: consumer response to the visual domain in product design. Design Studies 25, 547-577.

[3] Desmet, P. and Hekkert, P. 2007. Framework of product experience. International Journal of Design 1, 1, 57-66.

[4] Gross, A. and Silvennoinen, J. 2014. Surprise as design strategy in goal-oriented mobile applications. In Proceedings of the 5th International Conference on Applied Human Factors and Ergonomics, AHFE 2014, 4716-4726.

[5] Hassenzahl, M. and Tractinsky, N. 2006. User experience a research agenda. Behaviour \& Information Technology 25, 91-97.

[6] Hekkert, P., Snelders, D., and van Wieringen, P. C. W. 2003. 'Most advanced, yet acceptable ': Typicality and novelty as joint predictors of aesthetic preference in industrial design. British Journal of Psychology 94, 1, 111124.

[7] Husserl, E. 1936. The crisis of european sciences and transcendental phenomenology. Northwestern University Press, Evanston, IL.

[8] Jokinen, J. P. P. 2015. Emotional user experience: Traits, events and states. Int. J. of Human-Computer Studies 76, 67-77.

[9] Jokinen, J. P. P., Silvennoinen, J., Perälä, P., and Saariluoma, P. 2015. Quick affective judgments: Validation of a method for primed product comparisons. In
Proceedings of the SIGCHI Conference on Human Factors in Computing Systems - CHI '15, ACM Press, New York, NY, 2221-2230.

[10] Jostmann, N. B., Lakens, D., and Schubert, T. W. 2009. Weight as an embodiment of importance. Psychological Science 20, 9, 1169-1174.

[11] Kant, I. 1787. Critique of pure reason. English translation by Paul Guyer and Allen Wood (1998). Cambridge University Press, Cambridge.

[12] Karana, E. 2009. Meanings of materials. Doctoral dissertation. Delft University of Technology, Delft, the Netherlands.

[13] Kortum, P. 2008. HCI beyond the GUI. Design for haptic, speech, olfactory and other nontraditional interfaces. Morgan Kaufmann Publishers, Burlington, MA.

[14] Lindstrom, M. 2005. Brand sense: secrets behind the stuff we buy. Free Press, NY.

[15] Ludden, G. D. S., Schifferstein, H. N. J., and Hekkert, P. 2008. Surprise as a design strategy. Design Issues 24, 2 , 23-38.

[16] Ludden, G. D. S Schifferstein, H. N. J., and Hekkert, P. 2009. Visual-tactual incongruities in products as sources of surprise. Empirical Studies of the Arts 27, 1, 61-87.

[17] Ludden, G. D. S., Schifferstein, H. N. J., and Hekkert, P. 2012. Beyond Surprise: A Longitudinal Study on the Experience of Visual-Tactual Incongruities in Products. International Journal of Design 6, 1.

[18] Ludden, G. D. S. and van Rompay, T. J. L. 2015. How does it feel? Exploring touch on different levels of product experience. Journal of Engineering Design 26, 4-6, 1-12.

[19] Nagai, Y., and Georgiev, G. V. 2011. The role of impressions on users' tactile interaction with product materials: An analysis of associative concept networks. Materials and Design 32, 1, 291-302.

[20] Norman, D. 2004. Emotional design: Why we love (or hate) everyday things. Basic Books, NY.

[21] Osgood, C. E., May, W. H., and Miron, M. S. 1975. Crosscultural universals of affective meaning. University of Illinois, Press Urbana, IL.

[22] Posner, M. I., Nissen, M. J., and Klein, R. M. 1976. Visual dominance: an information-processing account of its origins and significance. Psychological review 83, 2, 157171.

[23] Rousi, R. 2013. Formidable Bracelet, Beautiful Lantern. In Design Science at the Intersection of Physical and Virtual Design. Berlin Heidelberg, Springer, 181-196.

[24] Saariluoma, P. 2003. Apperception, content-based psychology and design. In Human Behaviour in Design, U. Lindeman, Ed. Springer, Berlin, 72-78.

[25] Saariluoma P. and Jokinen, J. P. P. 2014. Emotional dimensions of user experience - a user psychological analysis. International Journal of Human-Computer Interaction 30, 4, 303-320.

[26] Scherer, K. R. and Ellgring, H. 2007. Multimodal expression of emotion: Affect programs or componential appraisal patterns?. Emotion 7, 1, 158-171. 
[27] Schifferstein, H. N. J. Otten, J. J. Thoolen, F., and Hekkert, P. 2010. The experimental assessment of sensory dominance in a product development context. Journal of Design Research 8, 2, 119-144.

[28] Schiphorst, T. 2009. Soft(n): Toward a somaesthetics of touch. In Proceeding of the Extended Abstracts on Human Factors in Computing Systems- CHI EA '09, ACM Press, New York, NY, 2427-2438.

[29] Smith, C. A. and Kirby, L. D. 2001. Toward delivering on the promise of appraisal theory. In Appraisal Process in Emotion, K. R. Scherer, A. Schorr, and T. Johnstone, Eds. Oxford University Press, New York, NY, 121-138.

[30] Thüring, M. and Mahlke, S. 2007. Usability, aesthetics and emotions in human-technology interaction. International Journal of Psychology 42, 4,253-264
[31] Wagoner, B. and Valsiner, J. 2005. Rating tasks in psychology: From static ontology to dialogical synthesis of meaning. Contemporary theorizing in psychology: Global perspectives, 197-213

[32] Zhang, P. 2013. The affective response model: a theoretical framework of affective concepts and their relationships in the ICT context. MIS Quarterly, 37, 1, 247-274.

[33] Zhou, H. and Fu, X. 2007. Understanding, measuring, and designing user experience: The causal relationship between the aesthetic quality of products and user affect. In HumanComputer Interaction. Interaction, Part I, J. Jacko, Ed. Springer, Berlin, 340-349. 